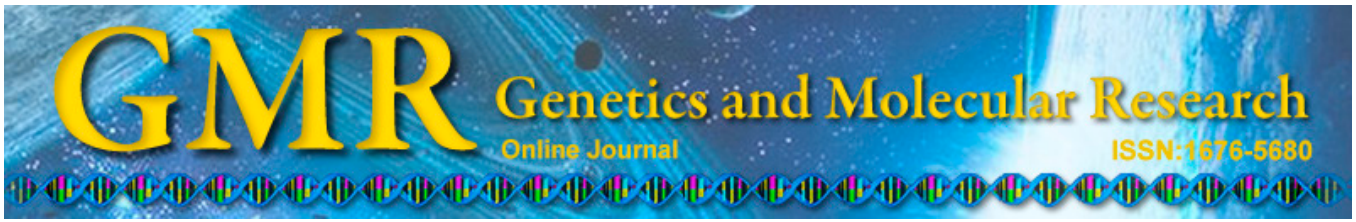

\title{
Gene expression, serum amino acid levels, and growth performance of pigs fed dietary leucine and lysine at different ratios
}

\author{
H. García ${ }^{1}$, A. Morales ${ }^{1}$, A. Araiza ${ }^{1}$, J.K. Htoo ${ }^{2}$ and M. Cervantes ${ }^{1}$ \\ ${ }^{1}$ Instituto de Ciencias Agrícolas, Universidad Autónoma de Baja California, \\ Mexicali, BC, México \\ ${ }^{2}$ Evonik Industries AG, Nutrition Research, Hanau, Germany \\ Corresponding author: M. Cervantes \\ E-mail: miguel_cervantes@uabc.edu.mx
}

Genet. Mol. Res. 14 (1): 1589-1601 (2015)

Received January 15, 2014

Accepted June 27, 2014

Published March 6, 2015

DOI http://dx.doi.org/10.4238/2015.March.6.6

\begin{abstract}
We examined 96 pigs $(28.1 \pm 0.83 \mathrm{~kg})$ to analyze the effect of Leu:Lys ratios on expression of the cationic amino acid transporters $b^{0,+}$ and CAT-1 in the jejunum and liver as well as myosin expression in 2 muscles to estimate the optimum standardized ileal digestible (SID) Leu:Lys ratio for growth rate and efficiency. A wheatand wheat bran-based diets were formulated to meet the requirements of SID amino acids other than Leu $(0.70 \%)$ and Lys $(0.80 \%)$. L-Leu was added to the basal diet in 5 SID Leu:Lys ratios $(88,100,120,140$, and $160 \%$ in diets 1-5). Tissue samples were collected from 8 pigs with ratios of 88,120 , and $160 \%$. Relative expression of $\mathrm{b}^{0,+}$, CAT-1, and myosin was analyzed. $b^{0,+}$ expression in the jejunum was higher but lower in the liver of pigs with the $120 \%$ ratio compared to those with the 88 or $160 \%$ ratio; myosin expression in longissimus dorsi was also higher in pigs with the $120 \%$ ratio $(\mathrm{P}<0.05)$. CAT- 1 was lower in the jejunum and longissimus dorsi of pigs with 120 or $160 \%$ ratios than in pigs with $88 \%$. Serum concentration of nearly all amino acids decreased with excess dietary Leu $(\mathrm{P}<0.05)$. The SID Leu:Lys of 104 and 109\%
\end{abstract}


optimized average daily gain and feed conversion ratio, respectively. Thus, the dietary Leu:Lys ratio affects the expression of genes coding for amino acid transporters and myosin, the availability of Lys, and the growth rate and efficiency in pigs.

Key words: Gene expression; Leu:Lys ratio; Pigs; Serum amino acids

\section{INTRODUCTION}

Leucine (Leu) is considered a functional amino acid (AA) because it stimulates protein synthesis in skeletal muscle by activating the mammalian target of rapamycin (mTOR) and enhancing the rates of mRNA translation (Anthony et al., 2000). Leu acutely stimulates muscle protein synthesis in fasted piglets by modulating the activation of mTOR and components of translation initiation (Suryawan et al., 2011), but only when other amino acids are supplied to maintain appropriate aminoacidemia (Wilson et al., 2010). Leu is also involved in the absorption of cationic AA (Bröer, 2008), which may affect the availability of lysine (Lys) for protein synthesis. Lys is transported across the apical and basolateral membranes of enterocytes through the transporters $\mathrm{b}^{0,+}$ and cationic amino acid transporter-1 (CAT-1), respectively (Majumder et al., 2009). The $\mathrm{b}^{0,+}$ system, which exchanges Leu for Lys (Torras-Llort et al., 2001), is the most important Lys transporter in the small intestine, and the absorption of Lys by $b^{0,+}$ is coupled with Leu efflux (Pineda et al., 2004). However, excess levels of dietary Leu appear to reduce Lys availability by decreasing the expression of $b^{0,+}$ (García-Villalobos et al., 2012). Leu stimulates muscle protein synthesis in pigs, and this stimulation is dependent on amino acid availability, but excess Leu may affect Lys absorption. Because typical pig diets formulated to meet Lys requirements (first limiting AA) contain excess Leu, the dietary Lys:Leu ratio is an important issue.

Studies regarding the optimal dietary Leu:Lys ratio for pigs are limited, although true digestible ratios of $100 \%$ (Chung and Baker, 1992; Augspurger and Baker, 2004) to $110 \%$ (Wang and Fuller, 1989) have been reported to be adequate in diets for 10-, 20-, and 30-kg pigs, using performance and nitrogen balance variables as indicators. These Leu:Lys ratios were determined before the Lys and Leu interaction for absorption and the Leu stimulation effect on protein synthesis stimulation were identified. Understanding the mechanism regarding how dietary Leu:Lys ratios affect the availability of all AA can be used to prevent negative interactions and to improve muscle protein synthesis. We hypothesized that the Leu:Lys ratio affects AA availability and muscle protein synthesis, which may affect both the rate and efficiency of growth in pigs. Lys, threonine, methionine, tryptophan, and valine are currently available in crystalline form and can be supplemented in the diet to eliminate excess AA such as Leu. Because myosin is the most abundant protein in muscle (Czerwinski and Martin, 1994), its expression can be used as indicator of protein synthesis in pigs. The objective of the present study was to analyze the effect of different Leu:Lys ratios on the expression of the cationic AA transporters $\mathrm{b}^{0,+}$ and CAT-1 in the jejunum, liver, longissimus dorsi (LD) muscle, and semitendinosus (ST) muscle, the expression of myosin in LD and ST, and the availability of AA (serum concentration, SC). In addition, the optimum standardized ileal digestible (SID) Leu:Lys ratio for maximizing the growth rate and feed efficiency in growing pigs was estimated. 


\section{MATERIAL AND METHODS}

\section{Animals and housing}

The pigs used in the experiment were cared for in accordance with the guidelines established in the Official Mexican Regulations on Animal Care (NOM-062-Z00-1999, 2001). A total of 96 crossbred pigs (Large White x Duroc) with initial body weight (BW) of $28.1 \pm$ $0.83 \mathrm{~kg}$ were used. The trial was run over 2 periods. In each period, there were 2 pigs ( 1 barrow and 1 gilt) per pen and 4 replicate pens for each dietary treatment ( 24 pens/period), for a total of 8 replicates per treatment. Pigs were assigned randomly to pens, but littermates were housed separately. The initial BW was balanced across pens. Pigs were housed in iron meshraised floor metabolism pens $(1.2 \times 1.2 \times 1.0 \mathrm{~m})$ equipped with a stainless-steel self-feeder and a nipple water drinker in a temperature-controlled room $\left(22^{\circ}-24^{\circ} \mathrm{C}\right)$. Feed was provided ad libitum. Pigs and feed disappearance were weighed on a weekly basis to calculate average daily weight gain (ADG), feed intake (ADFI), and feed conversion ratio (FCR). The average $\mathrm{BW}$ of the pigs at the end of the 3 -week study was $41.6 \pm 0.95 \mathrm{~kg}$.

\section{Dietary treatments}

Five wheat- and wheat bran-based experimental diets were formulated using analyzed AA contents of ingredients and published SID coefficients (AminoDat ${ }^{\mathbb{B}}$ 4.0, Evonik Industries, Hanau, Germany), to meet the requirements of AA other than Leu and Lys (NRC, 1998; Table 1). The SID Leu:Lys ratios in treatments $1-5$ were $88,100,120,140$, and 160 . These Leu:Lys ratios were obtained by adding different levels of corn gluten meal and free Leu to the diets. Corn gluten meal contains as much as 10X more Leu than wheat; in turn, wheat is one of the few feed ingredients whose Leu content is lower than the estimated requirement (NRC, 1998).

\begin{tabular}{|c|c|c|c|c|c|}
\hline Diets & 1 & 2 & 3 & 4 & 5 \\
\hline SID Leu:Lys ratio (\%) & 88 & 100 & 120 & 140 & 160 \\
\hline \multicolumn{6}{|l|}{ Ingredients $(\%)$} \\
\hline Wheat & 80.26 & 80.26 & 80.00 & 78.00 & 79.52 \\
\hline Wheat bran & 12.00 & 12.00 & 11.18 & 11.41 & 10.00 \\
\hline Corn starch & 3.00 & 2.90 & 3.00 & 3.00 & 3.00 \\
\hline Corn gluten meal & - & - & 2.50 & 3.50 & 3.50 \\
\hline Dicalcium phosphate & 0.35 & 0.35 & 0.25 & 0.36 & 0.37 \\
\hline Soybean oil & 0.94 & 0.94 & - & 0.64 & 0.36 \\
\hline Limestone & 1.33 & 1.33 & 1.36 & 1.32 & 1.31 \\
\hline Salt & 0.27 & 0.27 & 0.27 & 0.27 & 0.27 \\
\hline Mineral-vitamin Premix* & 0.20 & 0.20 & 0.20 & 0.20 & 0.20 \\
\hline L-lysine $\cdot \mathrm{HCl}$ & 0.65 & 0.65 & 0.63 & 0.62 & 0.62 \\
\hline L-leucine & - & 0.10 & 0.011 & 0.10 & 0.257 \\
\hline L-threonine & 0.32 & 0.32 & 0.26 & 0.25 & 0.25 \\
\hline DL-methionine & 0.16 & 0.16 & 0.11 & 0.10 & 0.10 \\
\hline L-tryptophan & 0.05 & 0.05 & 0.05 & 0.05 & 0.05 \\
\hline L-isoleucine & 0.16 & 0.16 & 0.10 & 0.10 & 0.10 \\
\hline L-valine & 0.18 & 0.18 & 0.12 & 0.10 & 0.10 \\
\hline L-phenylalanine & 0.09 & 0.09 & 0.01 & - & - \\
\hline L-histidine & 0.04 & 0.04 & 0.02 & 0.01 & 0.01 \\
\hline
\end{tabular}

*Supplied per kg of diet: vitamin $\mathrm{A}=4800 \mathrm{IU}$; vitamin $\mathrm{D} 3=800 \mathrm{IU}$; vitamin $\mathrm{E}=4.8 \mathrm{IU}$; vitamin $\mathrm{K} 3=1.6 \mathrm{mg}$; riboflavin, $4 \mathrm{mg}$; D-pantothenic acid $=7.2 \mathrm{mg}$; niacin = $16 \mathrm{mg}$; vitamin $\mathrm{B} 12=12.8 \mathrm{mg}$; $\mathrm{Zn}=64 \mathrm{mg} ; \mathrm{Fe}=64 \mathrm{mg}$; $\mathrm{Cu}=4 \mathrm{mg} ; \mathrm{Mn}=4 \mathrm{mg} ; \mathrm{I}=0.36 \mathrm{mg} ; \mathrm{Se}=0.13 \mathrm{mg}$. 
The Lys level was set at $0.80 \%$ SID Lys, which corresponds to approximately $92 \%$ of the Lys requirement for the genotype and BW of pigs used in the study (NRC, 1998). Thus, Leu was first limiting and Lys second limiting in the basal diet to avoid underestimation of the Leu to Lys ratio. Supplemental methionine, threonine, tryptophan, isoleucine, valine, phenylalanine, and histidine were added to the basal diet to exceed $(+7 \%)$ the recommended AA ratio, but were the same across diets for other AA (AminoDat $\left.{ }^{\mathbb{B}} 4.0\right)$ relative to the adequate level of Lys ( $0.85 \%$ SID basis). Surpluses of isoleucine and valine were avoided, but sufficient levels (NRC, 1998) of these AA were supplied in free form to eliminate any potential effect of the interactions between branch-chained AA. The net energy level was similar among diets (Table 2). Amino acid contents in feed ingredients, diets, and serum were determined by Evonik Industries (Llames and Fontaine, 1994).

\section{Table 2. Nutrient composition of the experimental diets.}

\begin{tabular}{|c|c|c|c|c|c|}
\hline & \multicolumn{5}{|c|}{ SID Leu:Lys ratio (\%) } \\
\hline & 88 & 100 & 120 & 140 & 160 \\
\hline \multicolumn{6}{|c|}{ Calculated NE, Ca, and available $P$ contents } \\
\hline $\mathrm{NE}(\mathrm{MJ} / \mathrm{kg})$ & 10.40 & 10.39 & 10.30 & 10.34 & 10.36 \\
\hline Total Ca (\%) & 0.61 & 0.61 & 0.60 & 0.61 & 0.61 \\
\hline Available $\mathrm{P}(\%)$ & 0.23 & 0.23 & 0.23 & 0.25 & 0.23 \\
\hline \multicolumn{6}{|c|}{ Analyzed CP and total AA contents (\%) } \\
\hline $\mathrm{CP}$ & 13.92 & 14.03 & 15.19 & 15.63 & 15.99 \\
\hline Arginine & 0.65 & 0.64 & 0.70 & 0.69 & 0.70 \\
\hline Histidine & 0.35 & 0.35 & 0.37 & 0.36 & 0.36 \\
\hline Isoleucine & 0.57 & 0.55 & 0.59 & 0.60 & 0.61 \\
\hline Leucine & 0.84 & 0.92 & 1.12 & 1.30 & 1.48 \\
\hline Lysine & 0.84 & 0.84 & 0.87 & 0.86 & 0.90 \\
\hline Methionine & 0.34 & 0.32 & 0.33 & 0.33 & 0.34 \\
\hline Phenylalanine & 0.65 & 0.64 & 0.68 & 0.70 & 0.70 \\
\hline Threonine & 0.66 & 0.60 & 0.66 & 0.62 & 0.63 \\
\hline Tryptophan & 0.20 & 0.21 & 0.20 & 0.21 & 0.21 \\
\hline Valine & 0.72 & 0.69 & 0.74 & 0.72 & 0.74 \\
\hline
\end{tabular}

\section{Tissue collection}

Four pigs each from treatments 1, 3, and 5 (Leu:Lys ratio, 88, 120, and 160\%, respectively) were fasted overnight for $9 \mathrm{~h}$; at the end of the 21-day trial, each pig was allowed to consume $650 \mathrm{~g}$ feed. Next, $2.5 \mathrm{~h}$ after the last feeding, all pigs were euthanized by electrical stunning and exsanguination to collect samples from small intestine (jejunum) mucosa, liver, and the LD and ST muscles. Samples of mucosa scratched from middle jejunum, liver, LD, and ST (approximately 0.5-1.0 g) were collected into 2-mL Eppendorf microtubes and immediately frozen in liquid nitrogen. Blood samples from the carotid artery $(10 \mathrm{~mL})$ were collected to analyze the $\mathrm{SC}$ of free $\mathrm{AA}$. All samples were stored at $-82^{\circ} \mathrm{C}$ until analysis.

\section{Total RNA extraction and purification}

Samples of the jejunum mucosa, liver, LD, and ST were treated to extract total RNA using the Trizol reagent (Invitrogen, Carlsbad, CA, USA) as reported by Méndez et al. (2011). Purified RNA was then eluted with $30 \mu \mathrm{L}$ RNase-free water and stored at $-82^{\circ} \mathrm{C}$. The concentration of total RNA was determined spectrophotometrically (Helios $\beta$, Thermo Electron Co., 
Waltham, MA, USA) at $260 \mathrm{~nm}$, and RNA purity was assessed by using the $\mathrm{A}_{260} / \mathrm{A}_{280}$ ratio, which ranged from 1.8-2.0 (Sambrook and Russell, 2001). The integrity of total RNA was evaluated by gel electrophoresis on $1 \%$ agarose gels. All RNA samples were of good quality with a 28S:18S rRNA ratio of approximately 2.0:1 (Sambrook and Russell, 2001).

\section{Reverse transcription}

Approximately $2 \mu \mathrm{g}$ total RNA was treated with $1 \mathrm{U}$ DNase I (1 U/ $\mu \mathrm{L}$; Invitrogen) and $6 \mu \mathrm{L} 5 \mathrm{X}$ reverse transcription buffer in a $30-\mu \mathrm{L}$ reaction completed with diethylpyrocarbonatetreated water; the reaction was carried out for $15 \mathrm{~min}$ at room temperature and another 15 min at $70^{\circ} \mathrm{C}$ to stop the reaction. Reverse transcription was initiated with DNase-treated RNA samples, adding $1 \mu \mathrm{L}$ random primers ( $150 \mathrm{ng} / \mu \mathrm{L}$; Invitrogen) and $1 \mu \mathrm{L}$ dNTPs (10 $\mu \mathrm{M}$ each). The reaction was incubated at room temperature and then chilled on ice for $1 \mathrm{~min}$. Next, $3 \mu \mathrm{L}$ dithiothreitol $(0.1 \mathrm{M}), 1 \mu \mathrm{L}$ ribonuclease inhibitor ( $40 \mathrm{U} / \mu \mathrm{L}$; RNase OUT, Invitrogen), and $2 \mu \mathrm{L} 5 \mathrm{X}$ reverse transcription buffer were added to the reaction and incubated at $42^{\circ} \mathrm{C}$ for 2 min to stabilize the reaction before adding $1 \mu \mathrm{L}$ reverse transcriptase enzyme $(200 \mathrm{U} / \mu \mathrm{L}$; RTSuperscript III, Invitrogen). The reaction was incubated at $42^{\circ} \mathrm{C}$ for $50 \mathrm{~min}$. The mixture was incubated at $70^{\circ} \mathrm{C}$ for $15 \mathrm{~min}$ and then chilled on ice to stop the reaction. cDNA samples were quantified spectrophotometrically and diluted to a final concentration of $50 \mathrm{ng} / \mu \mathrm{L}$.

\section{Real-time polymerase chain reaction (PCR)}

Specific primers for the AA transporters $\mathrm{b}^{0,+}$, CAT-1, and myosin (heavy chain 4 of isoform IIB) mRNA were designed based on their published sequences at GenBank (Table 3). Type IIB fibers account for approximately $80 \%$ of the total fibers in some pig muscles (Czerwinski and Martin, 1994; Davoli et al., 2003) and are extensively expressed in the LD and ST of pigs (Lefaucheur et al., 2002). Additionally, a housekeeping 18S rRNA gene was used as an endogenous control to normalize variations in mRNA levels. End-point PCR was carried out to standardize the amplification conditions for each pair of primers. To confirm the specificity of the PCR products related to its mRNA, a sample of each PCR product was purified using a commercial kit (PureLink, PCR Purification kit; Invitrogen) and sequenced at the Davis Sequencing Facility (Davis, CA, USA).

\begin{tabular}{|c|c|c|c|c|}
\hline mRNA & Primer & $\begin{array}{l}\text { Location (bp) } \\
\text { on the template }\end{array}$ & Sequence & $\begin{array}{l}\text { Amplicon } \\
\text { size (bp) }\end{array}$ \\
\hline \multicolumn{5}{|l|}{ CAT-1 (GenBank: AY371320) } \\
\hline & Forward & $4239-4258$ & 5'-GTCGGTTGCAAAGACCATTT-3' & 329 \\
\hline & Reverse & $4548-4567$ & 5'-GAGCGGTGCTGACAACAGTA-3' & \\
\hline \multicolumn{5}{|l|}{$\mathrm{b}^{0,+}$ AT (SLC7A9) (GenBank: EF127857) } \\
\hline & Reverse & $545-562$ & 5'-GCCCGCTGATGATGATGATGA-3' & \\
\hline \multirow[t]{2}{*}{ Myosin, heavy chain 4 (GenBank: NM_001123141) } & Forward & $4582-4599$ & 5'-AGATTTCTGACCTGACTG-3' & 320 \\
\hline & Reverse & $4904-4921$ & 5'-ТСТCССТCСАТСТTCTTC-3' & \\
\hline \multicolumn{4}{|l|}{ 18S rRNA (GenBank: AY265350) } & 295 \\
\hline & Reverse & $511-530$ & 5'-TAGAGGGACAAGTGGCGTTC-3' & \\
\hline
\end{tabular}


Expression of $\mathrm{b}^{0,+}$, CAT-1, and myosin was estimated by quantitative PCR (qPCR) assays, using the Maxima SYBR Green/ROX qPCR Master Mix (Fermentas, Corp., Vilnius, Lithuania) into a Chromo 4-DNA Engine with the MJ Opticon Monitor 3.1 software (BioRad, Hercules, CA, USA). The equipment was calibrated using a standard curve using the $18 \mathrm{~S}$ rRNA cloned into a TOPO vector 4.0. The standard curve was obtained using known concentrations of 100-fold serial dilutions of cDNA. The qPCRs contained $50 \mathrm{ng}$ cDNA, 0.5 $\mu \mathrm{M}$ of each specific primer, $12.5 \mu \mathrm{L} 2 \mathrm{X}$ SYBR green/ROX qPCR Master Mix, and DNase/ RNase-free water to a final volume of $25 \mu \mathrm{L}$. 18S rRNA was used as a housekeeping gene to normalize the amount of amplified DNA. PCR conditions used for the amplification and quantification were an initial denaturing stage $\left(95^{\circ} \mathrm{C}\right.$ for $\left.1 \mathrm{~min}\right)$, followed by 45 cycles of amplification (denaturing at $95^{\circ} \mathrm{C}$ for $30 \mathrm{~s}$; annealing at $56^{\circ} \mathrm{C}$ for $15 \mathrm{~s}$; and extension at $72^{\circ} \mathrm{C}$ for $30 \mathrm{~s})$; and a melting curve program $\left(60^{\circ}-90^{\circ} \mathrm{C}\right)$. Fluorescence was measured at the end of each cycle and at every $0.2^{\circ} \mathrm{C}$ during the melting program.

\section{Analysis of free amino acids in serum}

Blood samples were centrifuged at $500 \mathrm{~g}, 4^{\circ} \mathrm{C}$ for $10 \mathrm{~min}$ to separate serum from blood cells, and serum was deproteinized using an Ultrafree-MC 10,000 nominal molecular weight limit filter unit (Millipore, Bedford, MA, USA) at $5000 \mathrm{~g}, 4^{\circ} \mathrm{C}$ for $30 \mathrm{~min}$ (Sunde et al., 2003). The supernatant filtrate was derivatized using Waters AccQ-Tag reagent. AA analysis was performed by high-performance liquid chromatography according to the method described by Llames and Fontaine (1994).

\section{Statistical analysis}

Analyses of variance were performed using the general linear model of SAS (Statistical Analysis System 9.1, SAS Institute, Cary, NC, USA). Three contrasts were constructed to compare the effect of Leu:Lys ratios on gene expression and serum AA $\left(\mathrm{C}_{1}, 88 v s 120 ; \mathrm{C}_{2}\right.$, $120 v s 160 ; C_{3}, 88 v s$ 160). For growth performance variables, the pen was the experimental unit. For the best possible fit to the response data, a two-slope linear broken-line regression (Robbins et al., 2006) was used to estimate the optimum dietary Leu:Lys ratio at which the performance (ADG and FCR) response was maximized. Probability levels of $\mathrm{P} \leq 0.05$, and $0.05<\mathrm{P} \leq 0.10$ were defined as significant differences and tendencies, respectively.

\section{RESULTS}

One pig from treatment 2 died from non-experimental-related reasons; the remaining animals were healthy throughout the experiment. Real-time qPCR assays were validated by sequencing the final products of $\mathrm{b}^{0,+}$, CAT-1, myosin, and $18 \mathrm{~S}$ rRNA, which showed $100 \%$ homology with their expected sequences acquired from GenBank. 18S rRNA expression was very stable, and its content was used as an endogenous control to normalize the expression of other genes in response to various stimuli (Liao et al., 2009). Thus, in this study, we also normalized the relative expression of $\mathrm{b}^{0,+}$, CAT-1, and myosin mRNA to $18 \mathrm{~S}$ rRNA expression, using the $18 \mathrm{~S}$ rRNA expression levels in the small intestine epithelia and muscles.

The relative expression values of the cationic AA transporters and myosin are presented 
in Table 4. The expression of $\mathrm{b}^{0,+}$ in the jejunum was higher in pigs fed the $120 \%$ compared to the $88 \%$ Leu:Lys ratio $(\mathrm{P}=0.013)$ and $160 \%$ Leu:Lys ratio $(\mathrm{P}=0.045)$. No difference was observed between the 88 and $160 \%$ Leu:Lys ratios $(\mathrm{P}=0.575)$. In the liver, the expression of $\mathrm{b}^{0,+}$ was lower in pigs fed the $120 \%$ compared to both the $88 \%(\mathrm{P}=0.002)$ and $160 \%(\mathrm{P}=$ $0.005)$ Leu:Lys ratios; however, there was no difference between the 88 and $160 \%$ ratios $(\mathrm{P}=$ 0.595). The expression of $\mathrm{b}^{0,+}$ in LD and ST was not affected $(\mathrm{P}>0.10)$. Generally, the highest and lowest expression levels of $\mathrm{b}^{0,+}$ in pigs were observed in jejunum and the ST muscle, respectively. CAT-1 expression in the jejunum was lower in pigs fed the $120 \%(\mathrm{P}=0.009)$ or the $160 \%(\mathrm{P}=0.020)$ Leu:Lys ratio compared to the $88 \%$; but no difference was found between the 120 and $160 \%$ Leu:Lys ratios $(\mathrm{P}=0.743)$. The Leu:Lys ratio did not affect CAT-1 expression in the liver and ST $(\mathrm{P}>0.10)$. In the LD, CAT-1 expression was higher in pigs fed the $88 \%$ Leu:Lys ratio, as compared with those fed the $120 \%(\mathrm{P}=0.003)$, and was generally higher than in pigs fed the $160 \%$ ratio $(\mathrm{P}=0.099)$; pigs fed the $120 \%$ ratio expressed more CAT-1 than those fed the $160 \%$ ratio $(\mathrm{P}=0.050)$. In general, the highest CAT-1 expression was observed in the LD muscle, whereas expression was lowest in the jejunum. Myosin expression in the LD was higher in pigs fed the $120 \%$ Leu:Lys ratio compared with those fed the $88 \%$ (P $=0.044)$ or $160 \%$ ratio $(P=0.041)$, but no difference was observed between the 88 and $160 \%$ ratios. In the ST, myosin expression was generally higher in pigs fed the $120 \%$ compared to those fed the $160 \%$ Leu:Lys ratio $(\mathrm{P}=0.086)$, but no difference was observed between the 88 and $120 \%(\mathrm{P}=0.266)$ or $160 \%(\mathrm{P}=0.441)$ ratios.

Table 4. Effect of dietary SID Leu:Lys ratios on the relative expression of genes coding for $b^{0,+}$ and CAT-1 in the jejunum, liver, and the longissimus (LD) and semitendinosus (ST) muscles, and myosin in the LD and ST muscles of pigs (arbitrary units; ratio of $\mathrm{b}^{0,+}$ mRNA:18S rRNA) ${ }^{1}$.

\begin{tabular}{|c|c|c|c|c|c|c|c|}
\hline \multirow[t]{2}{*}{ AA transporter } & \multicolumn{3}{|c|}{ SID Leu:Lys (\%) } & \multirow[t]{2}{*}{ SE } & \multicolumn{3}{|c|}{$P$ values ${ }^{2}$} \\
\hline & 88 & 120 & 160 & & $\mathrm{C}_{1}$ & $\mathrm{C}_{2}$ & $\mathrm{C}_{3}$ \\
\hline \multicolumn{8}{|l|}{$\mathrm{b}^{0,+}$} \\
\hline Jejunum & 0.081 & 0.760 & 0.224 & 0.178 & 0.013 & 0.045 & 0.575 \\
\hline Liver & 0.162 & 0.033 & 0.145 & 0.021 & 0.002 & 0.005 & 0.595 \\
\hline LD & 0.015 & 0.015 & 0.004 & 0.007 & 0.963 & 0.311 & 0.332 \\
\hline ST & 0.003 & 0.003 & 0.002 & 0.001 & 0.891 & 0.682 & 0.586 \\
\hline \multicolumn{8}{|l|}{ CAT-1 } \\
\hline Jejunum & 0.278 & 0.109 & 0.130 & 0.044 & 0.009 & 0.743 & 0.020 \\
\hline Liver & 0.051 & 0.021 & 0.076 & 0.025 & 0.416 & 0.152 & 0.495 \\
\hline LD & 1.283 & 0.178 & 0.783 & 0.192 & 0.003 & 0.050 & 0.099 \\
\hline $\mathrm{ST}$ & 0.007 & 0.011 & 0.022 & 0.006 & 0.703 & 0.219 & 0.121 \\
\hline \multicolumn{8}{|l|}{ Myosin } \\
\hline LD & 8.546 & 19.534 & 8.338 & 3.055 & 0.044 & 0.041 & 0.963 \\
\hline ST & 1.874 & 3.293 & 0.919 & 0.818 & 0.266 & 0.086 & 0.441 \\
\hline
\end{tabular}

${ }^{1}$ Each mean represents 8 replicate pigs per treatment. ${ }^{2}$ Contrasts for Leu:Lys ratios: $\mathrm{C}_{1}, 88$ vs 120; $\mathrm{C}_{2}, 120$ vs 160 ; $\mathrm{C}_{3}, 88$ vs 160 .

Serum values of free AA are shown in Table 5. Increasing the Leu:Lys ratio from 88 to $120 \%$ increased serum $\operatorname{Arg}(P=0.039)$, Leu $(P=0.014)$, and $P$ he $(P=0.012)$, decreased valine $(\mathrm{P}=0.050)$, and tended to reduce isoleucine $(\mathrm{P}=0.068)$ and Met $(\mathrm{P}=0.076)$. A further increase from 120 to $160 \%$ decreased serum $\operatorname{Arg}(P=0.002)$, Lys, and Phe $(P=0.001)$. Serum isoleucine $(\mathrm{P}=0.044)$, Lys $(\mathrm{P}=0.008)$, and valine $(\mathrm{P}=0.030)$ were lower, $\mathrm{Arg}$ tended to be lower $(\mathrm{P}=0.086)$, and serum Leu was higher $(\mathrm{P}=0.003)$ in pigs fed the $160 \%$ compared to those fed the $88 \%$ ratio. 
Table 5. Effect of dietary SID Leu:Lys ratios on the concentration of free amino acids in serum of growing pigs ${ }^{1}$.

\begin{tabular}{|c|c|c|c|c|c|c|c|}
\hline \multirow[t]{2}{*}{ Amino acid } & \multicolumn{3}{|c|}{ SID Leu:Lys (\%) } & \multirow[t]{2}{*}{ SE } & \multicolumn{3}{|c|}{$\mathrm{P}_{\text {values }}{ }^{2}$} \\
\hline & 88 & 120 & 160 & & $\mathrm{C}_{1}$ & $\mathrm{C}_{2}$ & $\mathrm{C}_{3}$ \\
\hline Arginine & 4.00 & 4.79 & 3.37 & 0.23 & 0.039 & 0.002 & 0.086 \\
\hline Isoleucine & 3.50 & 2.20 & 2.02 & 0.44 & 0.068 & 0.793 & 0.044 \\
\hline Leucine & 2.01 & 3.67 & 4.26 & 0.39 & 0.014 & 0.310 & 0.003 \\
\hline Lysine & 4.38 & 4.90 & 3.05 & 0.28 & 0.225 & 0.001 & 0.008 \\
\hline Methionine & 1.25 & 0.90 & 0.72 & 0.21 & 0.076 & 0.319 & 0.014 \\
\hline Phenylalanine & 2.30 & 2.82 & 2.04 & 0.16 & 0.012 & 0.001 & 0.145 \\
\hline Threonine & 6.09 & 5.32 & 5.44 & 0.31 & 0.136 & 0.286 & 0.208 \\
\hline Valine & 9.69 & 4.88 & 4.15 & 1.53 & 0.050 & 0.742 & 0.030 \\
\hline
\end{tabular}

${ }^{1}$ Each mean represents 8 replicate pigs per treatment. ${ }^{2}$ Contrasts for Leu:Lys ratios: $\mathrm{C}_{1}, 88$ vs $120 ; \mathrm{C}_{2}, 120$ vs 160 ; $\mathrm{C}_{3}, 88$ vs 160 .

The performance results are presented in Table 6. There was a linear and quadratic (P $<0.01)$ response in the ADG of pigs as the SID Leu:Lys ratio increased from 88 to $160 \%$. As a result, the final BW increased in a linear and quadratic $(\mathrm{P}<0.01)$ manner with an increasing Leu:Lys ratio. In contrast, ADFI decreased linearly and the FCR showed a quadratic response $(\mathrm{P}<0.01)$ with an increased Leu:Lys ratio. The optimum dietary SID Leu:Lys ratio for ADG and FCR were estimated by using the two-slope linear broken-line regression analysis and found to be $104 \%\left(r^{2}=0.93\right.$; Figure 1$)$ and $109 \%\left(r^{2}=0.96\right.$; Figure 2$)$, respectively.

\begin{tabular}{|c|c|c|c|c|c|c|c|c|}
\hline \multirow[b]{2}{*}{ Item } & \multicolumn{5}{|c|}{ SID Leu:Lys (\%) } & \multirow[t]{2}{*}{ SE } & \multicolumn{2}{|c|}{$P$ values } \\
\hline & 88 & 100 & 120 & 140 & 160 & & Linear $^{2}$ & Quad. $^{3}$ \\
\hline \multicolumn{9}{|c|}{ Body weight $(\mathrm{kg})$} \\
\hline Initial & 28.58 & 27.41 & 28.24 & 27.75 & 28.25 & 1.308 & 0.935 & 0.682 \\
\hline Final & 41.68 & 42.73 & 42.52 & 41.05 & 40.72 & 0.325 & 0.001 & 0.002 \\
\hline $\mathrm{ADG}(\mathrm{kg})$ & 0.644 & 0.698 & 0.689 & 0.618 & 0.603 & 0.016 & 0.003 & 0.002 \\
\hline ADFI (kg) & 1.40 & 1.42 & 1.36 & 1.30 & 1.31 & 0.034 & 0.008 & 0.778 \\
\hline FCR $(g / g)$ & 2.17 & 2.03 & 1.97 & 2.11 & 2.16 & 0.054 & 0.698 & 0.006 \\
\hline
\end{tabular}

${ }^{1}$ Each mean represents 16 replicate pens (1 barrow, 1 gilt) per treatment. ${ }^{2}$ Contrast $\mathrm{P}$ values for linear effect. ${ }^{3}$ Contrast $\mathrm{P}$ values for quadratic effect.

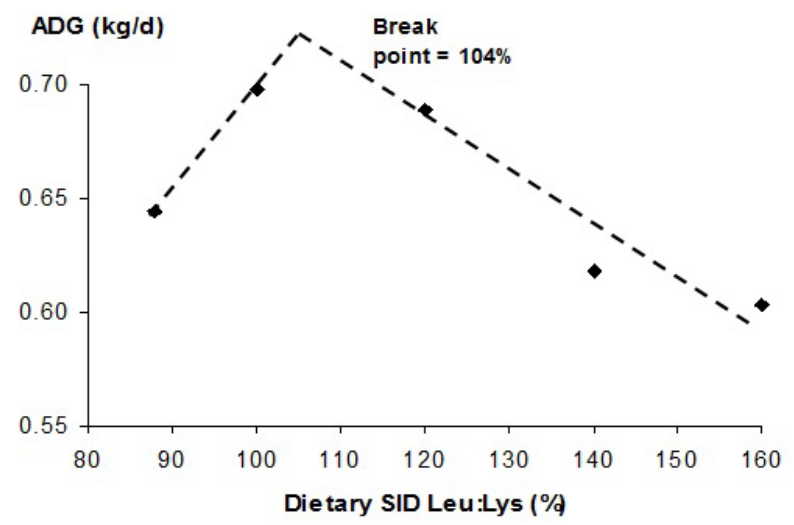

Figure 1. Fitted two-slope linear broken-line of average daily gain (ADG) as a function of standardized ileal digestible (SID) Leu:Lys in 25- to 45-kg pigs. Data points (lozenges) represent treatment means ( $\mathrm{N}=8$ observations per treatment mean). The optimum SID Leu:Lys determined by two-slope broken-line model was 104\% [Y=714.7 - 4.5 (104- $\left.\mathrm{x})^{2}-2.15(\mathrm{x}-104) ; \mathrm{r}^{2}=0.93\right]$. 


\section{$\mathrm{FCR}(\mathrm{kg} / \mathrm{kg})$}

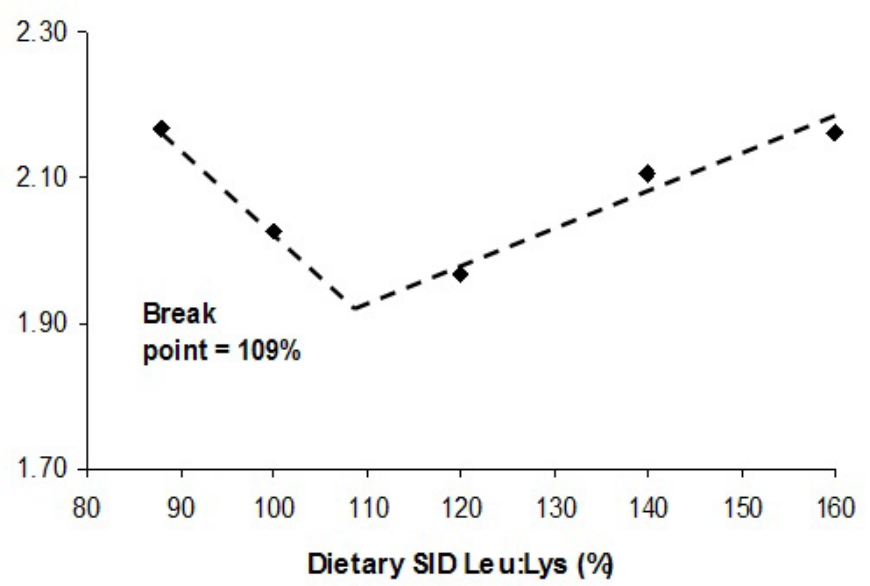

Figure 2. Fitted two-slope linear broken-line of feed conversion ratio (FCR) as a function of standardized ileal digestible (SID) Leu:Lys in 25- to 45-kg pigs. Data points (lozenges) represent treatment means ( $\mathrm{N}=8$ observations per treatment mean). The optimum SID Leu:Lys determined by two-slope broken-line model was $109 \%$ [Y $=1.927$ $\left.+0.012(109-x)^{2}-0.005(x-109) ; r^{2}=0.96\right]$.

\section{DISCUSSION}

We examined whether variations in the dietary Leu:Lys ratio affect the expression of 2 cationic AA transporters $\left(\mathrm{b}^{0,+}\right.$ and CAT-1) and myosin as well as the SC of AA, as indicators of AA availability in muscle protein synthesis. In addition, the SID Leu:Lys ratio that maximizes the growth rate and feed efficiency in growing pigs was estimated.

Lys is transported across the cell membrane by $b^{0,+}$ and CAT-1 (Majumder et al., 2009). The $\mathrm{b}^{0,+}$ system exchanges Leu for Lys (Torras-Llort et al., 2001), and the intestinal absorption of Lys by $b^{0,+}$ is coupled with Leu efflux (Pineda et al., 2004). As reported in several studies (Hatzoglou et al., 2004; Bröer, 2008) and proposed by Liao et al. (2009), the expression of cationic AA transporters represents their functional activity. Thus, expression values of the genes analyzed in the present experiment are thought to reflect the abundance of their respective encoded proteins. In this study, pigs fed a diet with the $120 \%$ Leu:Lys ratio increased $b^{0,+}$ expression in the jejunum by approximately 9- and 3-fold compared with those fed the 88 or 160\% Leu:Lys ratio. Similarly, García-Villalobos et al. (2012) reported that excess Leu in a wheat-based diet with a $160 \%$ Leu:Lys ratio and adequate Lys content reduced $\mathrm{b}^{0,+}$ expression by approximately $70 \%$ in the jejunum. These results and those of García-Villalobos et al. (2012) indicate that either a deficiency or excess of Leu in the diet negatively affects Lys absorption. In contrast to the jejunum, $\mathrm{b}^{0,+}$ expression in the liver was lower in pigs fed the $120 \%$ Leu:Lys ratio compared with the 88 and $160 \%$ ratios. Because $b^{0,+}$ was more highly expressed in the jejunum of pigs fed the $120 \%$ ratio, increased Lys flow from the small intestine to the liver was expected. Supply of AA reduces but low delivery increases the activity of the transporter (adaptive regulation theory; Hatzoglou et al., 2004). Therefore, the expected high Lys supply to the liver of pigs fed the $120 \%$ ratio may explain the reduced $\mathrm{b}^{0,+}$ expression in the liver. Regarding $b^{0,+}$ expression in the LD and ST, Vekony et al. (2001) reported that $b^{0,+}$ is 
mainly expressed in epithelial cells. In this study, the expression of $b^{0,+}$ in these muscles was less than $1 \%$ of that in the jejunum.

The CAT-1 transporter is a high-affinity Na-independent transporter of L-arginine and L-Lys whose expression level is modulated by growth factors, hormones, and nutrients (Hatzoglou et al., 2004). CAT-1 gene expression increases when AA are limited and reduces in the abundance of AA; this regulation takes place at the level of mRNA synthesis and mRNA stability (Majumder et al., 2009). Thus, mRNA abundance in pigs fed different dietary AA levels appears to reflect transporter abundance. In the present study, pigs fed the $120 \%$ Leu:Lys ratio showed the lowest expression of CAT-1 in the jejunum, which coincides with the highest expression of $b^{0,+}$ in the jejunum. Based on the adaptive theory (Hatzoglou et al., 2004), the reduced CAT-1 expression suggests higher extracellular availability of Lys in pigs fed the $120 \%$ ratio. In agreement with these results, myosin expression in the LD of pigs fed the $120 \%$ ratio was more than 2-fold higher compared to that in pigs fed either the 88 or $160 \%$ ratio. CAT-1 is primarily expressed in non-epithelial cells (Vekony et al., 2001). Accordingly, in the present study, the average expression of CAT- 1 in LD muscle was approximately 400 -fold that in the jejunum. Notably, CAT-1 expression in LD muscle was more than 50-fold higher than in ST muscle, suggesting the existence of not only tissue-related differences, but also muscle type-related differences in the expression of cationic AA transport systems.

Myosin is the major component of thick filaments and the most abundant of all muscle proteins (Czerwinski and Martin, 1994). According to Lefaucheur et al. (2002), type IIB fibers, which account for approximately $80 \%$ of the total fibers in some pig muscles, are extensively expressed in the ST and LD of pigs. Gunawan et al. (2007) reported higher expression of myosin IIB isoform in the LD compared with the ST in pigs. In this study, myosin was expressed in both muscles, but the expression in LD was approximately 6-fold higher compared to that in ST. Furthermore, pigs fed the diet containing the 120\% Leu:Lys ratio expressed approximately 2 -fold more myosin in both muscles compared to pigs fed the $160 \%$ ratio. Leu that is either infused (Wilson et al., 2010) or ingested (Rieu et al., 2007) appears to stimulate muscle protein synthesis, but only if sufficient amounts of the other essential AA are available (Wilson et al., 2010). Although pigs that consumed the $160 \%$ ratio diet ingested more Leu, their myosin expression was lower than those that consumed the $120 \%$ ratio diet, suggesting reduced availability of other AA such as Lys. Notably, pigs fed the diet containing the $120 \%$ Leu:Lys ratio showed the highest expression of myosin in both muscles as well as $\mathrm{b}^{0,+}$ in jejunum. According to Drummond et al. (2010), the expression of AA transporters is a unique regulatory mechanism associated with the muscle protein anabolic response after AA availability increases. These results suggest an association between the dietary Leu:Lys ratio, the absorption of Lys, and the synthesis of protein in muscle.

Exogenous protein is a principal source of increased free amino acids in plasma collected within the first $4 \mathrm{~h}$ post-prandial in humans (Adibi and Mercer, 1973); thus, the level of dietary AA appears to reflect their SC values. In the current study, blood samples used for AA analyses were collected $2.5 \mathrm{~h}$ post-prandial. The SC of Lys did not differ between pigs fed the diet containing the 88 or $120 \%$ Leu:Lys ratio, but SC was approximately $40 \%$ lower in pigs with the $160 \%$ than in those with the $120 \%$ ratio. A reduction in serum Lys can be explained as the result of either lower Lys intake, higher protein accretion that increases cellular Lys uptake, or impaired Lys absorption. Lys intake of pigs fed the $120 \%$ ratio did not differ from that of pigs fed the $160 \%$ Leu:Lys ratio, and thus a lower Lys intake does not explain the lower serum Lys in pigs fed the $160 \%$ ratio. Myosin expression in the LD and ST of pigs fed the $160 \%$ 
ratio was approximately 40 and $30 \%$, respectively, of that in pigs fed the $120 \%$ ratio, so the higher protein accretion in pigs fed the $160 \%$ ratio was also discharged. In contrast, expression of $\mathrm{b}^{0,+}$ was lower in pigs fed the $160 \%$ compared to the $120 \%$ ratio. Therefore, lower serum Lys appears to result from the negative effect of dietary excess Leu on the absorption of Lys.

Serum Leu in weaned pigs fed excess Leu diets (Edmonds and Baker, 1987; Langer and Fuller, 2000; Wiltafsky et al., 2010) are higher than in pigs fed non-excess Leu diets. In agreement with the results of previous studies, we found that the SC of Leu was 80 and $120 \%$ higher in pigs with the 120 or $160 \%$ Leu:Lys ratio, respectively, compared with pigs fed the $88 \%$ ratio. In contrast, the SC of isoleucine and valine in pigs fed the 120 and $160 \%$ Leu:Lys ratios decreased to less than $50 \%$ of that in pigs fed the diet with the $88 \%$ ratio. These results are also consistent with previous reports (Edmonds and Baker, 1987; Wiltafsky et al., 2010), resulting from increased activity of the enzyme complex that catabolizes all 3 branched chain amino acids in pigs fed diets with excess Leu (Block et al., 1987; Wiltafsky et al., 2010). Furthermore, competitive inhibition for absorption among branched chain amino acids has been documented (Hagihira et al., 1961). Therefore, excess Leu is expected to increase the catabolism or inhibit the absorption of isoleucine and valine, explaining the reduced SC of these AA when excess Leu was provided in pigs fed the 120 and 160\% Leu:Lys ratios. These data are critical because most ingredients used to formulate practical diets contain excess Leu, and low-protein diets may be limiting in isoleucine and valine.

The ADG was maximized at an SID Leu:Lys of 100 to $120 \%$ and FCR was maximized at an SID Leu:Lys of $120 \%$. Interestingly, the highest ADG and best FCR of pigs in the current study coincided with the highest expression of $\mathrm{b}^{0,+}$ in the jejunum and myosin in LD, as well as the highest serum Lys. Furthermore, pigs fed the 160\% ratio had lower ADG, SC of Lys, and expression $b^{0,+}$ in the jejunum and myosin in LD. Because Lys was first limiting in all diets, combining the results of performance, expression of $\mathrm{b}^{0,+}$ and myosin, and the SC of Lys supports the hypothesis that the dietary Leu:Lys ratio affects the availability of Lys for growth. In contrast, increased catabolism of isoleucine and valine caused by excess Leu reduces the amount of available isoleucine and valine (Harper et al., 1984). Accordingly, in the present study, excess Leu reduced serum isoleucine and valine in pigs fed the $160 \%$ ratio diet; however, isoleucine and valine were not limiting in this diet because their serum values in pigs fed the 120 or $160 \%$ ratio did not differ, but ADG was higher in the $120 \%$ ratio pigs. Therefore, the level of Lys in typical diets containing excess Leu appears to be critical.

Excess dietary Leu appears to reduce ADFI (Edmonds and Baker, 1987; Wiltafsky et al., 2010) by decreasing the formation of serotonin (a neurotransmitter involved in feed intake regulation), as Leu also competes with Trp for transport across the blood-brain barrier into the brain (Henry et al., 1996). Furthermore, Ropelle et al. (2008) found that Leu decreased AMPdependent kinase and increased mTOR activity in the hypothalamus, leading to inhibition of neuropeptide Y, and concluded that AMP-dependent protein kinase and mTOR interact in the hypothalamus to regulate feed intake. In the present study, the linear decrease in the ADG as the Leu:Lys ratio increased from 100 to $160 \%$, was closely associated with the linear reduction in ADFI. However, based on the analyzed AA content of these diets, there was no difference between intake of the first limiting AA (Lys, Thr, Met, isoleucine, and valine). Thus, availability of AA (particularly Lys) rather than ADFI appears to explain the low ADG in pigs fed the excess Leu diets.

The optimum dietary SID Leu:Lys ratio was estimated to be 104\% for ADG and 109\% for FCR in the present study using 28- to 43-kg pigs. Using purified diets, the dietary optimal 
Leu:Lys has been estimated to be $100 \%$ for 10- to $20-\mathrm{kg}$ pigs (Chung and Baker, 1992) and $110 \%$ for 25- to 50-kg growing pigs (Wang and Fuller, 1989). Augspurger and Baker (2004), using corn-peanut meal-whey-SBM-based diets, determined the SID Leu requirement for 10to $20-\mathrm{kg}$ pigs to be approximately $1.05 \%$, which corresponds to an SID Leu:Lys of $100 \%$. In a study by Wiltafsky et al. (2010), the calculated SID Leu:Lys ratio in wheat-barley-soybean meal diets for 8- to $20-\mathrm{kg}$ pigs that produced the best growth response was from 105-107\%. Based on these and our current results, the optimal SID Leu:Lys of 100-110\% appears to be adequate for growing pig diets, regardless of the diet composition.

\section{CONCLUSIONS}

The dietary Leu:Lys ratio selectively affects the expression of genes coding for cationic AA transporters $\left(\mathrm{b}^{0,+}\right.$ and CAT-1) and myosin, the SC of nearly all essential AA, and the performance (ADG and FCR) of growing pigs. Although the Leu:Lys ratio also affected ADFI, daily AA intake did not differ. There appears to be a close relationship between the expression of $\mathrm{b}^{0,+}$ in the jejunum and myosin in the LD, the SC of Lys, the ADG and FCR, and the Leu:Lys ratio. Lys availability appears to be the limiting factor in excess Leu diets for growing pigs. Therefore, Lys intake and availability should be considered when the diets for pigs contain excess Leu (>140\% SID Leu:Lys).

\section{ACKNOWLEDGMENTS}

The National Science and Technology Council of México (CONACYT) is acknowledged for providing a scholarship to Héctor García. The authors also wish to thank Evonik Industries AG for partially funding this project.

\section{REFERENCES}

Adibi SA and Mercer DW (1973). Protein digestion in human intestine as reflected in luminal, mucosal, and plasma amino acid concentrations after meals. J. Clin. Invest. 52: 1586-1594.

Anthony JC, Anthony TG, Kimball SR, Vary TC, et al. (2000). Orally administered leucine stimulates protein synthesis in skeletal muscle of postabsorptive rats in association with increased eIF4F formation. J. Nutr. 130: 139-145.

Augspurger NR and Baker DH (2004). An estimate of the leucine requirement for young pigs. Anim. Sci. 79: 149-153.

Block KP, Aftring RP, Mehard WB and Buse MG (1987). Modulation of rat skeletal muscle branched-chain alpha-keto acid dehydrogenase in vivo. Effects of dietary protein and meal consumption. J. Clin. Invest. 79: 1349-1358.

Bröer S (2008). Amino acid transport across mammalian intestinal and renal epithelia. Physiol. Rev. 88: 249-286.

Chung TK and Baker DH (1992). Ideal amino acid pattern for 10-kilogram pigs. J. Anim. Sci. 70: 3102-3111.

Czerwinski M and Martin JM (1994). Effect of somatotropin on myosin expression in pigs. J. Anim. Sci. 72: 1204-1208.

Davoli R, Fontanesi L, Cagnazzo M, Scotti E, et al. (2003). Identification of SNPs, mapping and analysis of allele frequencies in two candidate genes for meat production traits: the porcine myosin heavy chain $2 \mathrm{~B}$ (MYH4) and the skeletal muscle myosin regulatory light chain 2 (HUMMLC2B). Anim. Genet. 34: 221-225.

Drummond MJ, Glynn EL, Fry CS, Timmerman KL, et al. (2010). An increase in essential amino acid availability upregulates amino acid transporter expression in human skeletal muscle. Am. J. Physiol. Endocrinol. Metab. 298: E1011-E1018.

Edmonds MS and Baker DH (1987). Amino acid excesses for young pigs: effects of excess methionine, tryptophan, threonine or leucine. J. Anim. Sci. 64: 1664-1671.

García-Villalobos H, Morales-Trejo A, Araiza-Pina BA, Htoo JK, et al. (2012). Effects of dietary protein and amino acid levels on the expression of selected cationic amino acid transporters and serum amino acid concentration in growing pigs. Arch. Anim. Nutr. 66: 257-270. 
Gunawan AM, Park SK, Pleitner JM, Feliciano L, et al. (2007). Contractile protein content reflects myosin heavy-chain isoform gene expression. J. Anim. Sci. 85: 1247-1256.

Hagihira H, Lin EC, Samiy AH and Wilson TH (1961). Active transport of lysine, ornithine, arginine and cystine by the intestine. Biochem. Biophys. Res. Commun. 4: 478-481.

Harper AE, Miller RH and Block KP (1984). Branched-chain amino acid metabolism. Annu. Rev. Nutr. 4: 409-454.

Hatzoglou M, Fernandez J, Yaman I and Closs E (2004). Regulation of cationic amino acid transport: the story of the CAT-1 transporter. Annu. Rev. Nutr. 24: 377-399.

Henry Y, Seve B, Mounier A and Ganier P (1996). Growth performance and brain neurotransmitters in pigs as affected by tryptophan, protein, and sex. J. Anim. Sci. 74: 2700-2710.

Langer S and Fuller MF (2000). Interactions among the branched-chain amino acids and their effects on methionine utilization in growing pigs: effects on nitrogen retention and amino acid utilization. Br. J. Nutr. 83: 43-48.

Lefaucheur L, Ecolan P, Plantard L and Gueguen N (2002). New insights into muscle fiber types in the pig. J. Histochem. Cytochem. 50: 719-730.

Liao SF, Vanzant ES, Harmon DL, McLeod KR, et al. (2009). Ruminal and abomasal starch hydrolysate infusions selectively decrease the expression of cationic amino acid transporter mRNA by small intestinal epithelia of foragefed beef steers. J. Dairy Sci. 92: 1124-1135.

Llames CR and Fontaine J (1994). Determination of amino acids in feeds: collaborative study. J. Assoc. Off. Anal. Chem. 77: 1362-1366.

Majumder M, Yaman I, Gaccioli F, Zeenko VV, et al. (2009). The hnRNA-binding proteins hnRNP L and PTB are required for efficient translation of the Cat-1 arginine/lysine transporter mRNA during amino acid starvation. Mol. Cell Biol. 29: 2899-2912.

Méndez V, Avelar E, Morales A, Cervantes M, et al. (2011). A rapid protocol for purification of total RNA for tissues collected from pigs at a slaughterhouse. Genet. Mol. Res. 10: 3251-3255.

NOM-062-ZOO-1999 (2001). Especificaciones Técnicas para la Producción, Cuidado y Uso de Los Animales de Laboratorio. Diario Oficial de la Federación, Ciudad de México.

NRC (1998). Nutrient Requirements of Pigs. 10th Revised edn. National Academy Press, Washington.

Pineda M, Wagner CA, Broer A, Stehberger PA, et al. (2004). Cystinuria-specific rBAT(R365W) mutation reveals two translocation pathways in the amino acid transporter rBAT-b0,+AT. Biochem. J. 377: 665-674.

Rieu I, Balage M, Sornet C, Debras E, et al. (2007). Increased availability of leucine with leucine-rich whey proteins improves postprandial muscle protein synthesis in aging rats. Nutrition 23: 323-331.

Robbins KR, Saxton AM and Southern LL (2006). Estimation of nutrient requirements using broken-line regression analysis. J. Anim. Sci. 84 (Suppl): E155-E165.

Ropelle ER, Pauli JR, Fernandes MF, Rocco SA, et al. (2008). A central role for neuronal AMP-activated protein kinase (AMPK) and mammalian target of rapamycin (mTOR) in high-protein diet-induced weight loss. Diabetes 57: 594605.

Sambrook J and Russell DW (2001). Molecular Cloning: A Laboratory Manual. 3rd edn. Cold Spring Harbor Laboratory Press, New York.

Sunde J, Kiessling A, Higgs D and Opstvedt J (2003). Evaluation of feed protein quality by measuring plasma free amino acids in Atlantic salmon (Salmo salar L.) after dorsal aorta cannulation. Aquac. Nutr. 9: 351-360.

Suryawan A, Orellana RA, Fiorotto ML and Davis TA (2011). Leucine acts as a nutrient signal to stimulate protein synthesis in neonatal pigs. J. Anim. Sci. 89: 2004-2016.

Torras-Llort M, Torrents D, Soriano-Garcia JF, Gelpi JL, et al. (2001). Sequential amino acid exchange across b(0,+)-like system in chicken brush border jejunum. J. Membr. Biol. 180: 213-220.

Vekony N, Wolf S, Boissel JP, Gnauert K, et al. (2001). Human cationic amino acid transporter hCAT-3 is preferentially expressed in peripheral tissues. Biochemistry 40: 12387-12394.

Wang TC and Fuller MF (1989). The optimum dietary amino acid pattern for growing pigs. 1. Experiments by amino acid deletion. Br. J. Nutr. 62: 77-89.

Wilson FA, Suryawan A, Gazzaneo MC, Orellana RA, et al. (2010). Stimulation of muscle protein synthesis by prolonged parenteral infusion of leucine is dependent on amino acid availability in neonatal pigs. J. Nutr. 140: 264-270.

Wiltafsky MK, Pfaffl MW and Roth FX (2010). The effects of branched-chain amino acid interactions on growth performance, blood metabolites, enzyme kinetics and transcriptomics in weaned pigs. Br. J. Nutr. 103: 964-976. 